\title{
Revealing the structural complexity of Prussian blue analogues: the case of $\mathrm{K}_{2} \mathrm{Cu}\left[\mathrm{Fe}(\mathrm{CN})_{6}\right]$
}

\author{
John Cattermull, ${ }^{\dagger}$, Krishnakanth Sada, ${ }^{\ddagger}$ Kevin Hurlbutt, ${ }^{\ddagger}$ Simon J. \\ Cassidy, ${ }^{\dagger}$ Mauro Pasta, ${ }^{*, \ddagger}$ and Andrew L. Goodwin*, \\ $\dagger$ Department of Chemistry, University of Oxford, Inorganic Chemistry Laboratory, South Parks \\ Road, Oxford OX1 3QR, U.K. \\ $\ddagger$ Department of Materials, University of Oxford, Parks Road, Oxford OX1 3PH, U.K. \\ E-mail: mauro.pasta@materials.ox.ac.uk; andrew.goodwin@chem.ox.ac.uk
}

\section{Abstract}

We report the synthesis, crystal structure, thermal response, and electrochemical behaviour of the Prussian blue analogue $(\mathrm{PBA}) \mathrm{K}_{2} \mathrm{Cu}\left[\mathrm{Fe}(\mathrm{CN})_{6}\right]$. From a structural perspective, this is the most complex PBA yet characterised: its triclinic crystal structure results from an interplay of cooperative Jahn-Teller order, octahedral tilts, and a collective 'slide' distortion involving $\mathrm{K}$-ion displacements. These different distortions give rise to two crystallographically-distinct $\mathrm{K}$-ion channels with different mobilities. Variable-temperature $\mathrm{X}$ ray powder diffraction measurements show that $\mathrm{K}$-ion slides are the lowest-energy distortion mechanism at play, as they are the only distortion to be switched off with increasing temperature. Electrochemically, the material operates as a $\mathrm{K}$-ion cathode with a high operating voltage, and an improved initial capacity relative to higher-vacancy PBA alternatives. On charging, $\mathrm{K}^{+}$ ions are selectively removed from a single $\mathrm{K}$-ion channel type and the slide distortions are again switched on and off accordingly. We discuss the functional importance of various aspects of structural complexity in this system, placing our discussion in the context of other related PBAs.

\section{Keywords}

Prussian blue analogues, K-ion batteries, cooperative Jahn-Teller order, distortion modes

\section{Introduction}

Many of the most important and interesting ceramic perovskites are systems in which there is strong interplay amongst different types of symmetry-lowering distortions. ${ }^{1-5}$ The manganites are arguably the most famous case, for which orbital, magnetic, lattice, and charge degrees of freedom interact; ${ }^{6}$ this interaction is the key to anomalous physical properties such as colossal magnetoresistance, for example. ${ }^{7,8}$ The concept of hybrid improper ferroelectricity is closely related, whereby carefully-chosen structural distortions-each of which preserves inversion symmetry-can nonetheless collectively break inversion symmetry and so drive a bulk ferroelectric response. ${ }^{9} \mathrm{We}^{10}$ and others ${ }^{11,12}$ have a particular interest in the extension of these same ideas to molecular perovskites-systems in which at least one of the $\mathrm{A}, \mathrm{B}$, or $\mathrm{X}$ components of the perovskite $\mathrm{ABX}_{3}$ structure type is molecular, rather than atomic. ${ }^{13}$

One key family of molecular perovskites is that of the Prussian blue analogues (PBAs) ${ }^{14-17}$ _famous and long-studied systems that are of particular currency in the context of K-ion battery materials [Fig. 1(a)]. ${ }^{18,19}$ They are inexpensive to make, employ earth-abundant elements, are accessible through solution-phase synthesis, and benefit from both high operating voltages and favourable charge rates. ${ }^{20}$ It is often considered a key design feature of PBA battery materials that their cubic structure type is relatively unaffected by charge/discharge cycles ${ }^{19}$ —especially in contrast to the substantial anisotropic swelling observed in e.g. layered cathode materials. ${ }^{21}$ However, it is becoming increasingly clear that PBAs in fact harbour a large number of different types of structural distortions. ${ }^{22,23}$ 


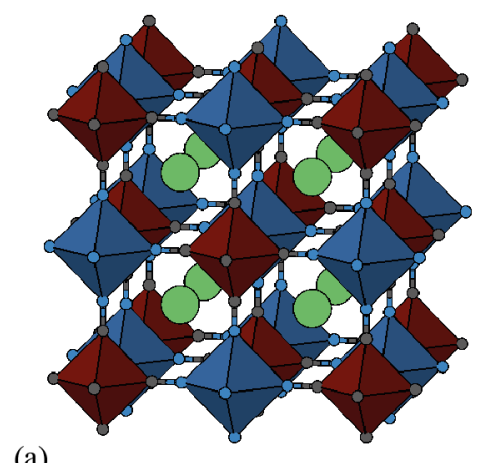

(a)

(c)

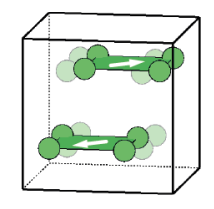

Figure 1: Idealised PBA structure and some common distortions. (a) The structure of low-vacancy PBAs (formula $\left.\mathrm{A}_{x} \mathrm{P}\left[\mathrm{R}(\mathrm{CN})_{6}\right]\right)$ is closely related to that of the double perovskites. P (blue) and $\mathrm{R}$ (dark-red) transition-metals alternate on a cubic lattice, and are connected via $\mathrm{P}-\mathrm{NC}-\mathrm{R}$ links. The A-site cations (green) are situated within the framework cavities. (b) In K-rich PBAs, neighbouring layers of $\mathrm{K}^{+}$ions slide in opposite directions along a common $\langle 110\rangle$ axis in order to maximise Coulombic interactions with the anionic framework. (c) Jahn-Teller active P-site cations (e.g. $\left.\mathrm{Cu}^{2+}\right)$ can drive cooperative Jahn-Teller order, in which the tetragonal distortion of $\mathrm{Cu}^{2+}$ coordination environments aligns along a single common $\langle 100\rangle$ axis.

And the implications of these distortions for material function are not at all clear; in particular, do they help or do they hinder?

It was in this context that we sought to prepare and to study the PBA material $\mathrm{K}_{2} \mathrm{Cu}\left[\mathrm{Fe}(\mathrm{CN})_{6}\right]$ : our motivation was the prospect of intentionally introducing a large degree of structural complexity in a material that ought to be electrochemically active. In this way we might assess the interplay of structural distortions and material function.

We rationalise our choice of composition in the following way. PBAs with high K-ion concentrations on the A-site undergo a 'slide' distortion that maximises Coulombic interactions with the cyanide framework and reduces the cubic PBA symmetry to monoclinic; ${ }^{22,24}$ this distortion occurs in $\mathrm{K}_{2} \mathrm{Mn}\left[\mathrm{Fe}(\mathrm{CN})_{6}\right]$ and $\mathrm{K}_{2} \mathrm{Fe}\left[\mathrm{Fe}(\mathrm{CN})_{6}\right.$ ], for example [Fig. 1(b)]. ${ }^{25,26}$ Our second ingredient is the use of $\mathrm{Cu}^{2+}$, which introduces a Jahn-Teller instability that ordinarily drives cooperative orbital order and a very different lattice distortion-now tetragonal-as in $\mathrm{Cu}\left[\mathrm{Pt}(\mathrm{CN})_{6}\right]$ [Fig. 1(c)]. ${ }^{27,28}$ And, finally, it is the accessibility of $\mathrm{Fe}^{3+/ 2+}$ electrochemistry that informs our decision to focus on a hexacyanoferrate salt.

Anticipating our results, we will come to show that $\mathrm{K}_{2} \mathrm{Cu}\left[\mathrm{Fe}(\mathrm{CN})_{6}\right]$ does indeed adopt a particularly complex structure (we understand it to be the most complex PBA yet characterised), and at the same time pos- sesses a variety of interesting electrochemical properties. We explore the interplay of these two aspects by using variable-temperature $\mathrm{X}$-ray diffraction measurements, on the one hand, to understand the hierarchy of distortion energy scales at play, and then ex situ diffraction measurements during charge/discharge cycles, on the other hand, to relate these distortions to the structural mechanism of $\mathrm{K}$-ion (de)insertion.

\section{Methods}

\section{Synthesis}

Based on the exploration of synthesis parameters reported in Ref. 25, we synthesised polycrystalline samples of $\mathrm{K}_{2} \mathrm{Cu}\left[\mathrm{Fe}(\mathrm{CN})_{6}\right]$ via a citrate-assisted precipitation in aqueous media. $\mathrm{CuNO}_{3} \cdot 3 \mathrm{H}_{2} \mathrm{O}$ (Sigma Aldrich, $1 \mathrm{mmol}$ ) was dissolved in an aqueous solution of potassium citrate (Sigma Aldrich, 1 M, $20 \mathrm{~mL}$ ). This solution was added dropwise to a stoichiometric aqueous solution of $\mathrm{K}_{4} \mathrm{Fe}(\mathrm{CN})_{6}$ (Sigma Aldrich, $20 \mathrm{~mL}$ ) at $80^{\circ} \mathrm{C}$ with stirring. The mixture was stirred for $2 \mathrm{~h}$, and then allowed to age for a further $2 \mathrm{~h}$. During this period a claret-red precipitate formed. This precipitate was isolated by centrifugation and washed with a 50:50 water:ethanol mixture in order to prevent the solid dispersing. The solid was dried in air at $70^{\circ} \mathrm{C}$.

\section{Materials Characterisation}

Elemental composition was determined by inductively coupled plasma mass spectrometry (ICP-MS) (Shimadzu ICPMS-2030) and water content was estimated using thermogravimetric analysis (TGA) (NETZSCH STA 449 F3 Jupiter) under $\mathrm{Ar}$ at a heating rate of $5{ }^{\circ} \mathrm{C} \mathrm{min}^{-1}$. Scanning electron microscopy (SEM) was carried out on a Zeiss Merlin microscope. Synchrotron X-ray diffraction (XRD) measurements were performed on I11 beamline of the Diamond Light Source operating with an X-ray wavelength of $0.826872 \AA$. The position-sensitive detector was used to collect diffraction patterns over the temperature range $30-450{ }^{\circ} \mathrm{C}$ with a hot-air blower. Ex situ X-ray powder diffraction measurements of the electrode materials were performed using a Rigaku Smartlab diffractometer $(\mathrm{Cu} \mathrm{K} \alpha)$. All Rietveld and Pawley refinements were carried out using the TOPAS-Academic software. ${ }^{29}$ 


\section{Electrochemical Characterisation}

Electrodes were prepared by mixing $70 \mathrm{wt} \%$ active material, $20 \mathrm{wt} \%$ carbon black (Super P), and $10 \mathrm{wt} \%$ poly(vinylidene fluoride) (PVDF) in a mortar and pestle with 1-methyl-2-pyrrolidone (NMP) to form a slurry. The slurry was pasted on carbon cloth (Fuel Cell Store ELAT hydrophilic carbon cloth) with a mass loading of around $10 \mathrm{mg} \mathrm{cm}^{-2}$, dried in air and then overnight at $80^{\circ} \mathrm{C}$ under vacuum. Electrochemical measurements were performed in flooded three-electrode cells sealed under $\mathrm{Ar}$ atmosphere in an aqueous solution of $\mathrm{K}_{2} \mathrm{SO}_{4}$ $(0.5 \mathrm{M})$ acidified to $\mathrm{pH} 1.8$ with $\mathrm{H}_{2} \mathrm{SO}_{4}$. $\mathrm{A} \mathrm{Hg} / \mathrm{Hg}_{2} \mathrm{SO}_{4}$ reference in saturated $\mathrm{K}_{2} \mathrm{SO}_{4}$ and a Pt counter electrode were used.

\section{Computational Methods}

Density-functional theory (DFT) calculations were performed using the Vienna Ab initio Simulation Package (VASP). ${ }^{30,31}$ Candidate structures were relaxed using the HSE06 functional. ${ }^{32,33}$ All calculations were $\Gamma$ point only with a planewave kinetic-energy cutoff of $520 \mathrm{eV}$. Electronic and ionic convergence criteria were $10^{-5} \mathrm{eV}$ and $0.05 \mathrm{eV}^{-1}$, respectively.

\section{Results and Discussion}

\section{Preparation and Characterisation of $\mathrm{K}_{2} \mathrm{Cu}\left[\mathrm{Fe}(\mathrm{CN})_{6}\right]$}

The chemical composition of our $\mathrm{K}_{2} \mathrm{Cu}\left[\mathrm{Fe}(\mathrm{CN})_{6}\right]$ sample, prepared as described above, was determined using ICP-MS measurements. ICP provides a robust measure of both $\mathrm{Fe}$ and $\mathrm{Cu}$ content, but is notoriously unreliable in determining potassium content, ${ }^{34}$ which must be deduced by consideration of charge balance. We found the $\mathrm{Fe} / \mathrm{Cu}$ ratio to be $0.979(8)$. The degree of hydration was estimated to be 0.23 on the basis of the mass-loss observed in TGA measurements. Collectively these measurements implied a composition of $\mathrm{K}_{1.96} \mathrm{Cu}\left[\mathrm{Fe}(\mathrm{CN})_{6}\right]_{0.98} \cdot 0.23 \mathrm{H}_{2} \mathrm{O}$; we use the simplified approximate formula $\mathrm{K}_{2} \mathrm{Cu}\left[\mathrm{Fe}(\mathrm{CN})_{6}\right]$ hereafter.

The ambient-temperature synchrotron X-ray diffraction pattern of $\mathrm{K}_{2} \mathrm{Cu}\left[\mathrm{Fe}(\mathrm{CN})_{6}\right]$ is shown in Fig. 2(a). The diffraction profile is surprisingly different to that of the monoclinic PBAs, such as $\mathrm{K}_{2} \mathrm{Mn}\left[\mathrm{Fe}(\mathrm{CN})_{6}\right]$; ${ }^{25}$ in particular, the very strongest low-angle reflections show further peak splitting than that allowed even in the already-low-symmetry monoclinic structure type [see inset to Fig. 2(a)]. Using the distortion mode refine- ment approach implemented within TOPAS, ${ }^{29}$ we obtained a structure solution in the triclinic space-group $P \overline{1}$ with an excellent fit-to-data $(R=1.95 \%)$. We will come to rationalise this particularly low-symmetry structure in terms of competing distortion modes. Details of the structural model are given in Table 1, and the structure itself is illustrated in Fig. 2(b); our refinement protocol is discussed in more detail in the SI.

Despite the low symmetry of this structure, our use of high-resolution synchrotron X-ray diffraction measurements has allowed us to obtain sensible atomic coordinates. For example, we find that the octahedral coordination geometry of the hexacyanoferrate groups is well preserved, and that even the $\mathrm{C}$ and $\mathrm{N}$ positions are reasonable despite the poor scattering contrast of these light elements in the presence of $\mathrm{K}, \mathrm{Fe}$, and $\mathrm{Cu}$. Importantly, the structural distortions we intended to introduce by choosing the $\mathrm{K}_{2} \mathrm{Cu}\left[\mathrm{Fe}(\mathrm{CN})_{6}\right]$ composition are evident in this structure solution. For example, the $\mathrm{K}$ atoms have displaced from their high-symmetry po-

Table 1: Crystallographic parameters for the $P \overline{1}$ structure of $\mathrm{K}_{2} \mathrm{Cu}\left[\mathrm{Fe}(\mathrm{CN})_{6}\right.$ ] at ambient temperature. In our Rietveld refinements we allowed $\mathrm{K}$ and $\mathrm{Fe}$ occupancies to vary from unity, obtaining the values $0.946(13)$ and $0.986(13)$ for K1 and $\mathrm{K} 2$, and 0.986(14) and 0.990(14) for $\mathrm{Fe} 1$ and $\mathrm{Fe} 2$, respectively.

\begin{tabular}{l|llll}
\hline$a / \AA$ & $7.0560(5)$ & & & \\
$b / \AA$ & $7.3401(6)$ & & & \\
$c / \AA$ & $9.8698(6)$ & & & \\
$\alpha /^{\circ}$ & $89.8890(10)$ & & & \\
$\beta /^{\circ}$ & $89.9083(11)$ & & & \\
$\gamma /^{\circ}$ & $86.154(10)$ & & & $B_{\mathrm{eq}} / \AA^{2}$ \\
$Z$ & 2 & & $z$ & $2.9(2)$ \\
$\mathrm{Atom}$ & $x$ & $y$ & $0.2495(7)$ \\
$\mathrm{K} 1$ & $-0.0378(5)$ & $0.5655(5)$ & $0.5(2)$ \\
$\mathrm{K} 2$ & $0.4917(5)$ & $0.0548(5)$ & $0.2519(7)$ & $1.01(3)$ \\
$\mathrm{Cu} 1$ & 0 & 0 & 0.5 & 1.01 \\
$\mathrm{Cu} 2$ & 0.5 & 0.5 & 0 & 1.01 \\
$\mathrm{Fe} 1$ & 0 & 0 & 0 & 1.01 \\
$\mathrm{Fe} 2$ & 0.5 & 0.5 & 0.5 & 1.01 \\
$\mathrm{C} 1$ & $0.763(3)$ & $0.874(3)$ & $0.0248(16)$ \\
$\mathrm{C} 2$ & $0.139(3)$ & $0.773(3)$ & $-0.0241(18)$ & 1.01 \\
$\mathrm{C} 3$ & $0.360(3)$ & $0.294(3)$ & $0.5387(16)$ & 1.01 \\
$\mathrm{C} 4$ & $0.735(3)$ & $0.364(3)$ & $0.4777(18)$ & 1.01 \\
$\mathrm{C} 5$ & $0.074(3)$ & $0.005(3)$ & $0.181(2)$ & 1.01 \\
$\mathrm{C} 6$ & $0.571(3)$ & $0.537(3)$ & $0.683(2)$ & 1.01 \\
$\mathrm{~N} 1$ & $0.636(2)$ & $0.781(2)$ & $0.0381(14)$ & 1.01 \\
$\mathrm{~N} 2$ & $0.255(2)$ & $0.659(2)$ & $-0.0095(16)$ & 1.01 \\
$\mathrm{~N} 3$ & $0.265(2)$ & $0.168(2)$ & $0.5509(14)$ & 1.01 \\
$\mathrm{~N} 4$ & $0.846(2)$ & $0.245(2)$ & $0.4878(16)$ & 1.01 \\
$\mathrm{~N} 5$ & $0.036(2)$ & $-0.006(2)$ & $0.297(2)$ & 1.01 \\
$\mathrm{~N} 6$ & $0.543(2)$ & $0.524(2)$ & $0.799(2)$ & 1.01 \\
\hline & & & & \\
\hline
\end{tabular}




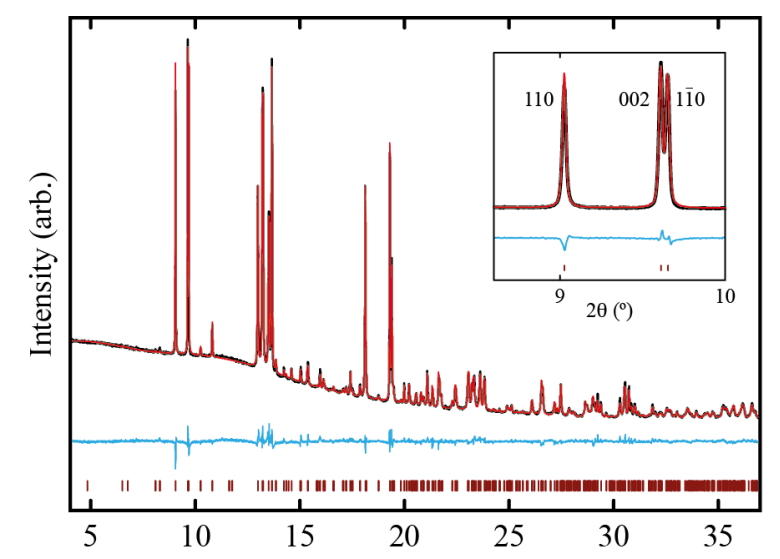

(a)

$2 \theta\left({ }^{\circ}\right)$

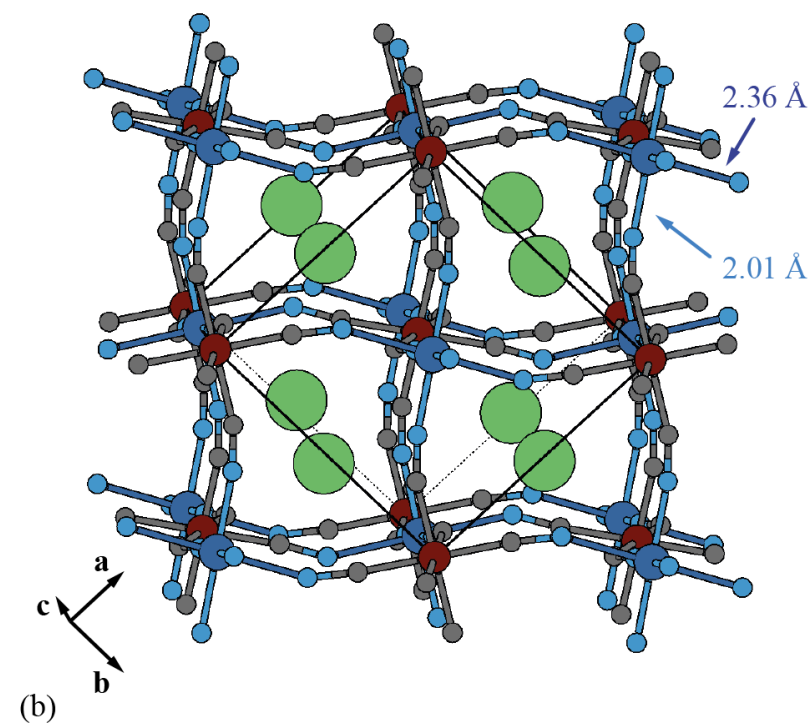

Figure 2: (a) Rietveld fit to the room-temperature synchrotron X-ray powder diffraction pattern $(\lambda=0.826872 \AA)$ of $\mathrm{K}_{2} \mathrm{Cu}\left[\mathrm{Fe}(\mathrm{CN})_{6}\right]$. Data are shown in black, fit in red, difference function in blue, and calculated reflection positions as dark-red tick marks. The inset shows a representative lowangle region of the pattern in which the triclinic splitting is very obvious - here between the 110 and $1 \overline{1} 0$ reflections. (b) Representation of the final structural model determined from our refinements. $\mathrm{K}$ atoms shown in green, $\mathrm{Cu}$ in dark blue, $\mathrm{Fe}$ in dark red, $\mathrm{C}$ in grey, and $\mathrm{N}$ in light blue. Note the presence of large-scale $\mathrm{K}$-ion off-centering. The $\mathrm{Cu}-\mathrm{N}$ bond lengths partition into 'short' and 'long' bonds, shown here as light and dark blue cylinders, respectively. The arrangement of the different $\mathrm{Cu}-\mathrm{N}$ bonds reflects collective Jahn-Teller order, with $\mathrm{Cu}^{2+}$ octahedra elongated along a direction close to $[110]$.

sitions by about $0.5 \AA$ to give precisely the same type of slide distortion seen in other K-rich PBAs (albeit that the magnitude of distortion is particularly large here). And of the six distinct $\mathrm{Cu}-\mathrm{N}$ bond lengths, two are significantly longer than the other four $(2.36 \AA$ vs $2.02 \AA)$, as expected for a Jahn-Teller-distorted octahedral $\mathrm{Cu}^{2+}$ coordination environment. ${ }^{1,28}$ Cooperative tilting of the transition-metal coordination polyhedra is also observed; the particular tilt system is given by the Glazer notation ${ }^{35} a^{0} a^{0} c^{+}$and is the simplest tilt distortion compatible with the $\mathrm{K}^{+}$slides we observe. ${ }^{22,36}$ An important feature of this structure is the existence of two symmetry-inequivalent $\mathrm{K}^{+}$sites, a point to which we will return in due course.

Further physical evidence for the adoption of a low symmetry structure type is given by scanning electron microscopy (SEM). Individual particles of $\mathrm{K}_{2} \mathrm{Cu}\left[\mathrm{Fe}(\mathrm{CN})_{6}\right]$ have an approximately cubic morphology, but on close inspection are clearly complex twins of crystallites with subtly non-orthogonal crystal axes (see SI for further discussion).

\section{Distortion-Mode Analysis}

In general, one ought to be sceptical of low-symmetry structure solutions, so it is natural to question: is there a logical reason as to why the crystal structure of $\mathrm{K}_{2} \mathrm{Cu}\left[\mathrm{Fe}(\mathrm{CN})_{6}\right]$ is triclinic?

We argue first by comparing against the known structure of $\mathrm{K}_{2} \mathrm{Mn}\left[\mathrm{Fe}(\mathrm{CN})_{6}\right]$, which has the monoclinic $P 2_{1} / n$ space-group symmetry common to many $\mathrm{K}$ rich PBAs. ${ }^{25}$ Formally, this monoclinic structure type is related to the idealised cubic PBA parent structure ( $F m \overline{3} m$ symmetry) by the combined activation of the slide distortion shown in Fig. 1(b) and a cooperative $a^{0} a^{0} c^{+}$octahedral tilt of the framework structure that always seems to accompany it. ${ }^{22,23}$ The former deformation transforms as the $\mathrm{X}_{5}^{+}$irreducible representation (irrep; note that we are using labels relative to the double-perovskite $F m \overline{3} m$ parent with B-site ions located at the cell origin) and the latter as $\mathrm{X}_{3}^{+}$; it is the interplay of these two distortion modes that reduces the PBA symmetry to $P 2_{1} / n{ }^{22}$ Replacing $\mathrm{Mn}^{2+}$ by the Jahn-Teller-active $\mathrm{Cu}^{2+}$ understandably leads to an additional distortion of the type illustrated in Fig. 1(c), which transforms as $\Gamma_{3}^{+}$. Using the ISOTROPY software, ${ }^{37,38}$ we find that this additional distortion reduces the crystal symmetry from $P 2_{1} / n$ to $P \overline{1}$, with the same cell orientation as observed in our Rietveld refinement. So, adding collective Jahn-Teller order to the monoclinic $\mathrm{K}_{2} \mathrm{Mn}\left[\mathrm{Fe}(\mathrm{CN})_{6}\right]$ structure type necessarily implies triclinic symmetry.

A related argument can be made by considering the structure of $\mathrm{RbCu}\left[\mathrm{Co}(\mathrm{CN})_{6}\right] .{ }^{39}$ This system has orthorhombic $C c c m$ space-group symmetry, which is understood as arising from the interplay of collective Jahn-Teller order of $\mathrm{Cu}^{2+}$ ions (again, $\Gamma_{3}^{+}$) with either the $a^{0} a^{0} c^{+}$tilt distortion $\left(\mathrm{X}_{3}^{+}\right)$or 'rod-like' $\mathrm{Rb}$ cation order $\left(\mathrm{X}_{4}^{+}\right)$. The group theory result is that any two of 
these three distortion types necessarily gives the third, so there is no way of telling from symmetry arguments alone which two of these three are physically responsible for symmetry lowering. Whatever the case, there is no off-centering of the $\mathrm{Rb}^{+}$ions in this orthorhombic structure. Replacing $\mathrm{Rb}^{+}$by the smaller $\mathrm{K}^{+}$and doubling the A-site cation content introduces the $\mathrm{X}_{5}^{+}$ slide distortion; again, ISOTROPY analysis indicates that this additional distortion lowers the crystal symmetry to $P \overline{1}$ as observed experimentally.

We illustrate these various symmetry relationships in Fig. 3, where we draw on the established visual language used to relate progressively complex tilt distortions in conventional perovskites. ${ }^{36,40,41}$ The key point is that one can consider the low-symmetry $P \overline{1}$ structure we observe as the inevitable consequence of introducing either cooperative Jahn-Teller order into the monoclinic K-rich PBA structure type, or K-ion-driven slides into the orthorhombic Jahn-Teller-ordered structure.

Just as the $C c c m$ structure of $\mathrm{RbCu}\left[\mathrm{Co}(\mathrm{CN})_{6}\right]$ contains two crystallographically-distinct A-site environments - in that case, one empty and the other occupied by $\mathrm{Rb}^{39}$ - $\mathrm{so}$ is it the case that there are two distinct $\mathrm{K}$ environments in our new $P \overline{1}$ structure of $\mathrm{K}_{2} \mathrm{Cu}\left[\mathrm{Fe}(\mathrm{CN})_{6}\right]$ (as noted above). The authors of Ref. 42 argued on the basis of Madelung constants that the resulting 'rod-like' $\mathrm{Rb}$ order has a physical basis, but our instinct is that there is no strong chemical driving force for this distinction in a system such as $\mathrm{K}_{2} \mathrm{Cu}\left[\mathrm{Fe}(\mathrm{CN})_{6}\right]$ where all $\mathrm{A}$ sites are occupied. Instead the existence of two K-ion sites is simply a crystallographic quirk that results from the other structural distortions with more obvious physical origins.

\section{Density Functional Theory Calcula- tions}

We used density functional theory (DFT) calculations as a further check on the validity of our structural model for $\mathrm{K}_{2} \mathrm{Cu}\left[\mathrm{Fe}(\mathrm{CN})_{6}\right]$. Starting from the lattice vectors and atomic coordinates determined in our Rietveld refinements, the crystal structures were fully relaxed using the HSE06 functional to account for strong electronic correlation. ${ }^{43}$ The relaxed unit cell dimensions are listed in Table 2, and differ by less than $1 \%$ from our experimental values. Individual atomic coordinates also showed relatively small deviations. The $\mathrm{Fe}$ and $\mathrm{Cu}$ atom positions do not vary; the $\mathrm{K}$ atoms shifted with a root-mean-squared (r.m.s.) displacement of $0.09 \AA$; and the $\mathrm{C}$ and $\mathrm{N}$ atoms showed the largest shifts, with r.m.s. displacements of 0.18 and $0.20 \AA$, respectively. Given the difficulty of refining $\mathrm{C}$ and $\mathrm{N}$ positions in
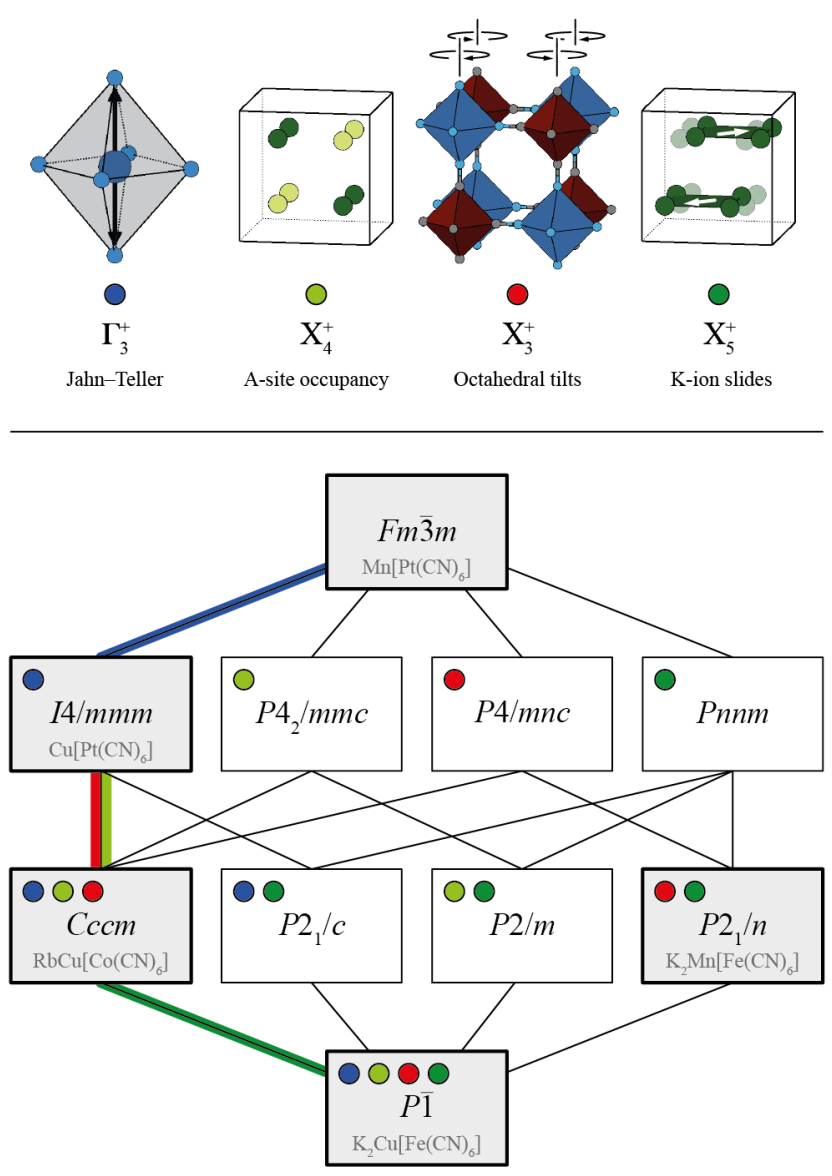

Figure 3: Symmetry relationships in distorted PBAs. The four key distortion types relevant to our study are (top; leftright) cooperative Jahn-Teller order, 'rod-like' A-site cation order, $a^{0} a^{0} c^{+}$octahedral tilts, and K-ion slides. Starting from the aristotypic double-perovskite, the symmetry map at the bottom of the figure represents the space-group symmetry that results from successive activation of each distortion type. Note that any two of the $\Gamma_{3}^{+}, \mathrm{X}_{4}^{+}$, and $\mathrm{X}_{3}^{+}$distortions necessarily activates the third. Combinations with known PBA exemplars are highlighted in grey. The path between $P \overline{1}$ and $C c c m$ structure types-which is key to the thermal and electrochemical response of $\mathrm{K}_{2} \mathrm{Cu}\left[\mathrm{Fe}(\mathrm{CN})_{6}\right]$-is highlighted in green as it corresponds to activation or deactivation of the K-ion slide distortion. We have used the space-group labels $P 2_{1} / c$ and $P 2_{1} / n$ for two of the distorted structure types to convey the point that the resulting structures are inequivalent; while either might be transformed to the other space-group setting, the unique axis is different in the two cases.

the presence of electron-rich elements from powder Xray diffraction data, we consider this difference entirely reasonable. Importantly, all of the distortion modes identified above-K-ion slides, collective Jahn-Teller order, and octahedral tilts-were evident also in this relaxed DFT structure. For completeness, the DFT atomic coordinates are given in the SI. 
Table 2: DFT $(0 \mathrm{~K})$ unit cell parameters for $\mathrm{K}_{2} \mathrm{Cu}\left[\mathrm{Fe}(\mathrm{CN})_{6}\right]$ and the corresponding differences relative to our experimental values measured at $295 \mathrm{~K}$.

\begin{tabular}{l|ll}
\hline Parameter & DFT value & Difference $(\%)$ \\
\hline$a / \AA$ & 7.092 & 0.51 \\
$b / \AA$ & 7.335 & 0.07 \\
$c / \AA$ & 9.842 & 0.28 \\
$\alpha{ }^{\circ}$ & 89.713 & 0.20 \\
$\beta /^{\circ}$ & 89.990 & 0.01 \\
$\gamma /^{\circ}$ & 85.520 & 0.74 \\
\hline
\end{tabular}

\section{High-Temperature Behaviour}

In order to determine the hierarchy of distortion energy scales in $\mathrm{K}_{2} \mathrm{Cu}\left[\mathrm{Fe}(\mathrm{CN})_{6}\right.$ ], we sought to characterise its behaviour on heating - after all, the thermal response of a material is dominated by activation of the lowestenergy deformations. ${ }^{44}$ We first used TGA to understand the compositional stability of the system; our results are shown in Fig. 4(a). Three regimes are evident. First, heating to $\sim 250{ }^{\circ} \mathrm{C}$ sees the loss of a small amount of surface and structural water, as is common for PBAs in general. ${ }^{45} \mathrm{~A}$ more substantive mass-loss event occurs around $250-320^{\circ} \mathrm{C}$, resulting in a solid that eventually decomposes above $425^{\circ} \mathrm{C}$.

Our variable-temperature synchrotron X-ray powder diffraction measurements focus on the temperature range $30-450{ }^{\circ} \mathrm{C}$ and are consistent with the TGA findings [Fig. 4(a)]. The ambient $P \overline{1}$ phase persists from room temperature until $\sim 250^{\circ} \mathrm{C}$. Within this regime a number of peaks coalesce and others disappear, suggesting a continuous ascent in symmetry (see, for example, the pair of peaks marked with an asterisk in Fig. 4(a)). On heating above $250^{\circ} \mathrm{C}$, the ambient phase is progressively lost, and two new phases grow in. One appears then disappears, and the other remains the dominant phase to the highest temperatures explored in our measurements. The diffraction pattern of this persistent phase appears close to that of a conventional cubic PBA for the highest temperatures probed in our measurements.

Focussing first on the thermal behaviour of the ambient $P \overline{1}$ phase, we carried out a series of sequential distortion-mode Rietveld refinements for the diffraction patterns measured at each temperature over the range $30-350^{\circ} \mathrm{C}$. We found the very strongest variation in distortion-mode amplitudes for those distortions related to the K-ion slide distortion (see SI). In fact, by $320^{\circ} \mathrm{C}$, the lattice strain associated with this distortion ( $\Gamma_{5}^{+}$irrep) has essentially vanished such that the diffraction pattern of $\mathrm{K}_{2} \mathrm{Cu}\left[\mathrm{Fe}(\mathrm{CN})_{6}\right]$ at this temperature is actually better described in the orthorhombic
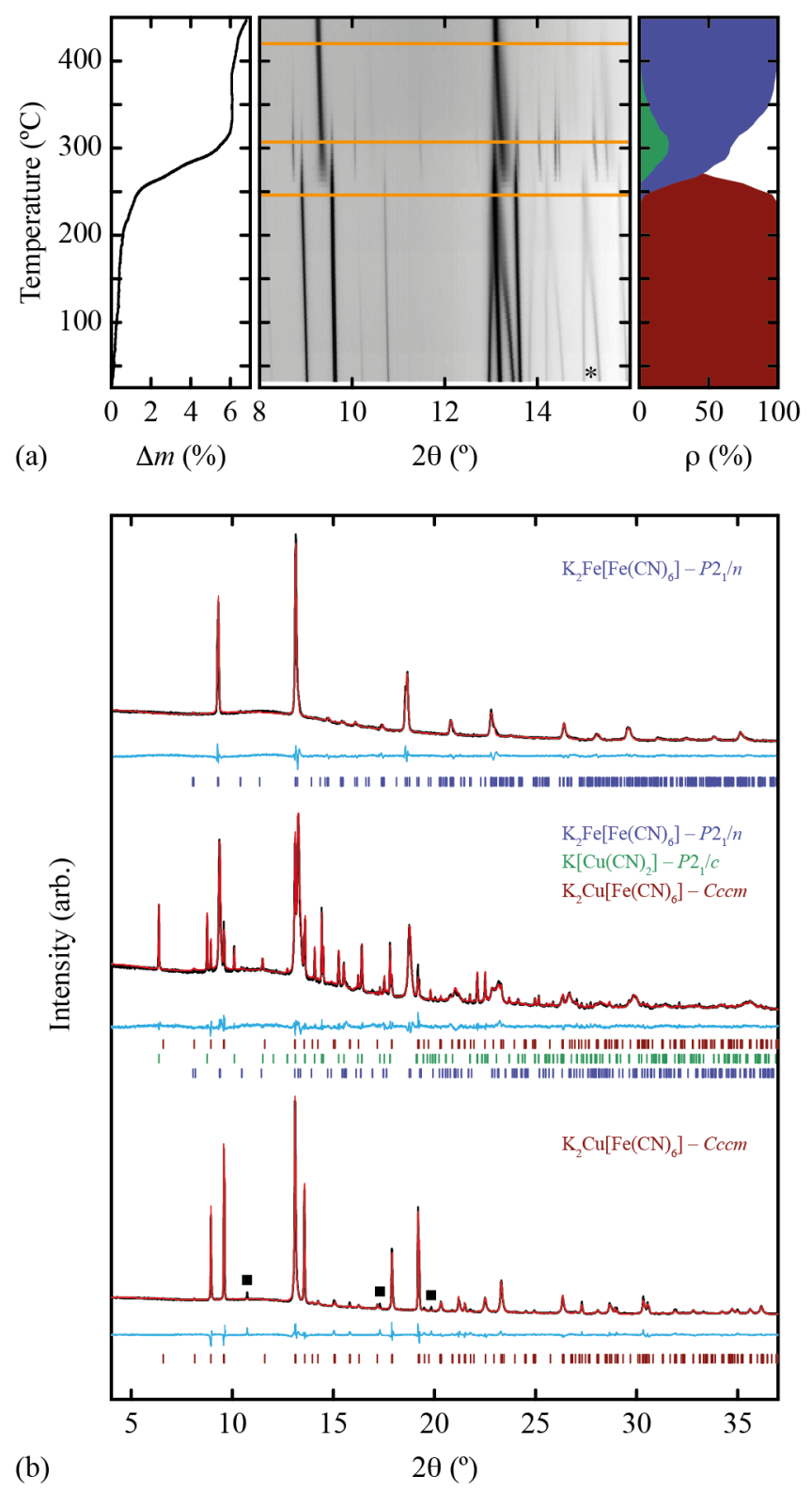

Figure 4: Variable-temperature structural response of $\mathrm{K}_{2} \mathrm{Cu}\left[\mathrm{Fe}(\mathrm{CN})_{6}\right]$. (a) The temperature dependence of (leftright) the relative mass loss $\Delta m$ measured using TGA, a representative section of the X-ray powder diffraction pattern $(\lambda=0.826872 \AA)$, and the phase fractions $\rho$ obtained using constrained Rietveld refinements. Here, dark red corresponds to the ambient $\mathrm{K}_{2} \mathrm{Cu}\left[\mathrm{Fe}(\mathrm{CN})_{6}\right]$ phase, green to $\mathrm{KCu}(\mathrm{CN})_{2}$, and dark blue to $\mathrm{K}_{2} \mathrm{Fe}\left[\mathrm{Fe}(\mathrm{CN})_{6}\right]$. (b) Constrained Rietveld fits to the $\mathrm{X}$-ray powder diffraction patterns measured at $420^{\circ} \mathrm{C}$ (top), $307^{\circ} \mathrm{C}$ (middle), and $246^{\circ} \mathrm{C}$ (bottom). The first of these corresponds to $\mathrm{K}_{2} \mathrm{Fe}\left[\mathrm{Fe}(\mathrm{CN})_{6}\right]$ at the point that its monoclinic distortion effectively vanishes; the second to the temperature at which all three crystalline phases are present; and the third to the first point at which the structure of $\mathrm{K}_{2} \mathrm{Cu}\left[\mathrm{Fe}(\mathrm{CN})_{6}\right]$ is better described by $C \mathrm{ccm}$ than $P \overline{1}$ space-group symmetry. The few weak peaks remaining that are foribdden in $C \mathrm{ccm}$ are indicated by filled squares. 
space-group $C c c m$ than in $P \overline{1}$. We show a fit to the data using this higher-symmetry space group in Fig. 4(b). The microscopic picture that emerges is that $\mathrm{K}$-ion displacements are most easily activated on heating, such that temperature switches off the slide distortion and its symmetry-lowering effect-all that remains is the cooperative Jahn-Teller distortion and octahedral tilts found in related systems with larger A-site cations (e.g. $\left.\mathrm{RbCu}\left[\mathrm{Co}(\mathrm{CN})_{6}\right]\right) .{ }^{39}$

We were able to match the diffraction profile of the high-temperture transient phase to that of potassium dicyanocuprate $(\mathrm{I}), \mathrm{KCu}(\mathrm{CN})_{2} .{ }^{46}$ The cyanide ion is well known to reduce copper(II) to copper(I), ${ }^{47,48}$ so the emergence of this phase implies the breaking of $\mathrm{Fe}-\mathrm{CN}$ bonds at this elevated temperature. $\mathrm{KCu}(\mathrm{CN})_{2}$ is understood to melt at around $290^{\circ} \mathrm{C}$, which is presumably why the diffraction pattern of this phase disappears on further heating. One possible decomposition pathway for $\mathrm{K}_{2} \mathrm{Cu}\left[\mathrm{Fe}(\mathrm{CN})_{6}\right]$ is the reaction

$$
\begin{gathered}
\mathrm{K}_{2} \mathrm{Cu}\left[\mathrm{Fe}(\mathrm{CN})_{6}\right] \rightarrow \mathrm{KCu}(\mathrm{CN})_{2}+\frac{1}{2}(\mathrm{CN})_{2}+ \\
\frac{1}{2} \mathrm{~K}_{2} \mathrm{Fe}\left[\mathrm{Fe}(\mathrm{CN})_{6}\right] .
\end{gathered}
$$

The mass-loss observed in our TGA measurements is broadly consistent with that expected for cyanogen evolution (see SI). Moreover, we find the second, persistent, high-temperature phase to be well modelled by the $P 2_{1} / n$ structure of $\mathrm{K}_{2} \mathrm{Fe}\left[\mathrm{Fe}(\mathrm{CN})_{6}\right] ;{ }^{26}$ the monoclinic distortion in this phase decreases with increasing temperature such that it has essentially vanished by $425^{\circ} \mathrm{C}$ and the structure is almost cubic. Key corresponding Rietveld fits are shown in Fig. 4(b), and the associated phase fractions are given in panel (a) of the same figure.

So, in summary, we find that $\mathrm{K}_{2} \mathrm{Cu}\left[\mathrm{Fe}(\mathrm{CN})_{6}\right]$ responds to heating by first unwinding the $\mathrm{K}$-ion slide distortion, and then by exsolving $\mathrm{Cu}^{2+}$, which is reduced by free cyanide to give $\mathrm{KCu}(\mathrm{CN})_{2}$ as a transient solid phase and the thermally-robust PBA $\mathrm{K}_{2} \mathrm{Fe}\left[\mathrm{Fe}(\mathrm{CN})_{6}\right]$. Of course it is possible that some $\mathrm{Cu}$ remains in this final $\mathrm{PBA}$ - our X-ray measurements would be insensitive to $\mathrm{Cu} / \mathrm{Fe}$ compositions-but the space-group symmetry rules out any cooperative JahnTeller distortion. As a final point, we note that not only are the K-ion slides the key thermally-activated distortion in this material, but the observed transition to $C c c m$ implies it is probably right to think of them as a fundamental distortion in their own right, and not simply a byproduct of other distortions, such as tilts. ${ }^{23}$

\section{Electrochemistry}

We turn now to the electrochemistry of $\mathrm{K}_{2} \mathrm{Cu}\left[\mathrm{Fe}(\mathrm{CN})_{6}\right]$, with a particular emphasis on understanding its struc-
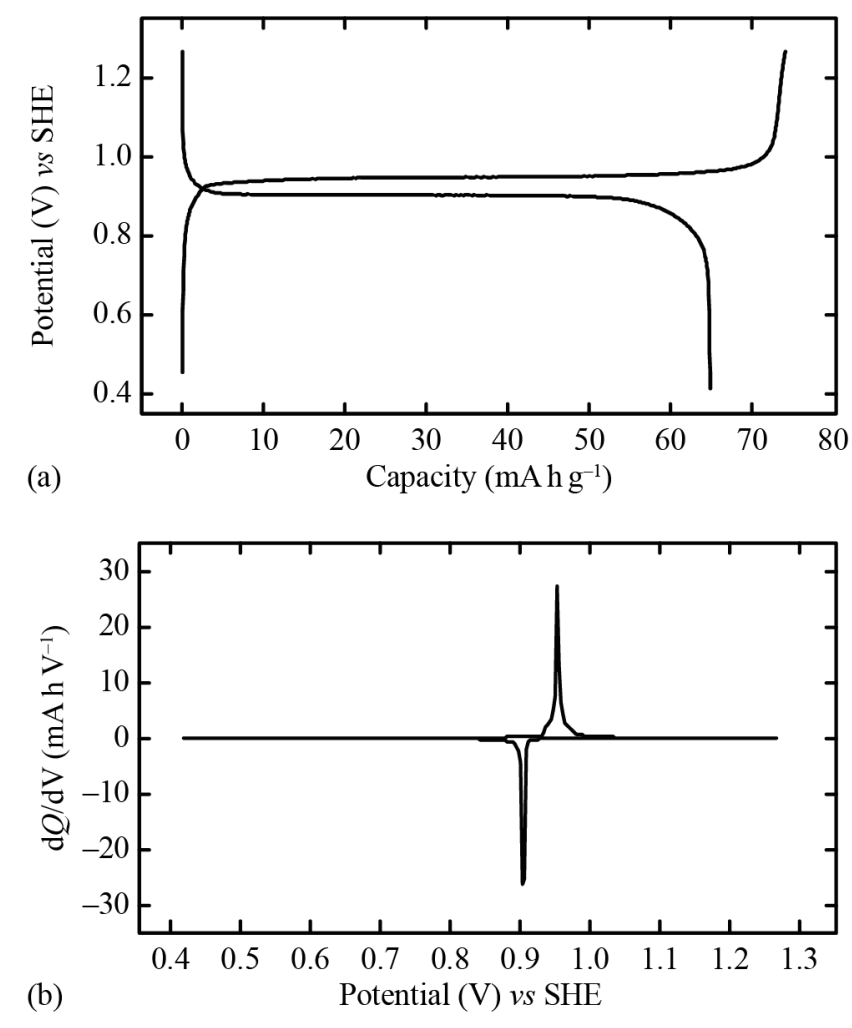

Figure 5: Electrochemical characterisation of $\mathrm{K}_{2} \mathrm{Cu}\left[\mathrm{Fe}(\mathrm{CN})_{6}\right]$. (a) The galvanostatic cycle measured at a cycling rate of $\mathrm{C} / 6$ shows a maximum specific capacity of $73.8 \mathrm{~mA} \mathrm{hg}^{-1}$ centred on $0.949 \mathrm{~V}$. The flat profile is characteristic of a two-phase mechanism. (b) The corresponding differential capacity function.

tural response to K-ion (de)insertion. For our electrochemical measurements, we used an aqueous cell setup designed to perform well at high operating potentials; the linear sweep voltammetry (LSV) shows good stability of the electrolyte in the upper potential limit of $1.265 \mathrm{~V}$ vs the standard hydrogen electrode (SHE) (see SI). Our results, obtained using a cycling rate of C/6, are shown in Fig. 5(a). The material cycles at a high voltage of $0.949 \mathrm{~V}$ vs SHE at the mid-composition on charging, with a capacity of $73.8 \mathrm{~mA} \mathrm{~h} \mathrm{~g}^{-1}$ on the first charge. This capacity is very close to the theoretical value for a vacancy-free and anhydrous $\mathrm{K}_{2} \mathrm{Cu}\left[\mathrm{Fe}(\mathrm{CN})_{6}\right.$ ] composition $\left(75.8 \mathrm{~mA} \mathrm{~h} \mathrm{~g}^{-1}\right)$, which is further evidence of the low-vacancy / highpotassium content of our sample. Not all capacity is recovered on subsequent discharge.

The profile of the galvanostatic cycle is characteristic of a biphasic reaction: there is a plateau in the potential measured that corresponds to a sharp peak in the differential capacity function [Fig. 5(b)]. A two-phase mechanism is also supported by the potentiostatic intermittent titration technique (PITT), which shows the characteristic bell-shaped $I-t$ curve that arises from delayed 
response of the current following each step in voltage (see SI).

There is an interesting comparison to be drawn between the behaviour we observe for $\mathrm{K}_{2} \mathrm{Cu}\left[\mathrm{Fe}(\mathrm{CN})_{6}\right.$ ] and that of the closely-related and well-established cathode material $\mathrm{K}_{0.71} \mathrm{Cu}\left[\mathrm{Fe}(\mathrm{CN})_{6}\right]_{0.72} .{ }^{18}$ With its large fraction of hexacyanoferrate vacancies, there is no long-range cooperative Jahn-Teller order in the latter; instead its crystal structure (which is very disordered) has cubic average symmetry. Cubic symmetry is maintained on $\mathrm{K}$-ion insertion/deinsertionthe presence of vacancies in that phase frustrating long-range order of any local distortions. ${ }^{22,49}$ This is why $\mathrm{K}_{0.71} \mathrm{Cu}\left[\mathrm{Fe}(\mathrm{CN})_{6}\right]_{0.72}$ cycles via a singlephase (solid-solution) mechanism. By contrast, we expect that the $\mathrm{K}$-ion slide distortion in the vacancyfree $\mathrm{K}_{2} \mathrm{Cu}\left[\mathrm{Fe}(\mathrm{CN})_{6}\right]$ will be switched off at a critical potassium content as $\mathrm{K}^{+}$ions are removed during charge. ${ }^{22,25}$ On the basis of the symmetry relationships shown in Fig. 3, one anticipates a transition to the $C \mathrm{ccm}$ structure-type at such a point, which would explain the two-phase mechanism we observe here.

To test this hypothesis, we carried out a series of ex situ powder X-ray diffraction measurements on $\mathrm{K}_{2} \mathrm{Cu}\left[\mathrm{Fe}(\mathrm{CN})_{6}\right]$ samples taken at five key points in the first charge/discharge cycle. Our results, which we proceed to explain, are shown in Fig. 6. The first measurement was taken prior to charging and is entirely consistent with the $P \overline{1}$ structure type determined in our higher-resolution synchrotron X-ray study discussed above. Halfway through the first charge, a particularly complex diffraction pattern is observed that then simplifies considerably at the point of full charge. That third measurement - which on the basis of our electrochemical results corresponds to the approximate composition $\mathrm{KCu}\left[\mathrm{Fe}(\mathrm{CN})_{6}\right]$ — can indeed be accounted for by a single phase with $C \mathrm{ccm}$ symmetry. The complex intermediate diffraction pattern at half-charge can then be fitted using a two-phase $P \overline{1} / \mathrm{Cccm}$ model, with intensities taken from the pristine and fully-charged patterns. Our measurements taken on discharge are similar in their implications. The final diffraction pattern is again characteristic of the $\mathrm{K}_{2} \mathrm{Cu}\left[\mathrm{Fe}(\mathrm{CN})_{6}\right] P \overline{1}$ structure type, albeit with significantly broadened reflections. And the pattern taken at the half-discharge point can again be fitted using a two-phase model. Full details of our fitting procedure and results of the various refinements are given in the SI.

So, just as $\mathrm{K}_{2} \mathrm{Cu}\left[\mathrm{Fe}(\mathrm{CN})_{6}\right]$ responds to thermal activation by switching off the $\mathrm{K}$-ion slides and ascending from $P \overline{1}$ to $C c c m$ symmetry, so too does electrochemical K-ion extraction have the same effect.

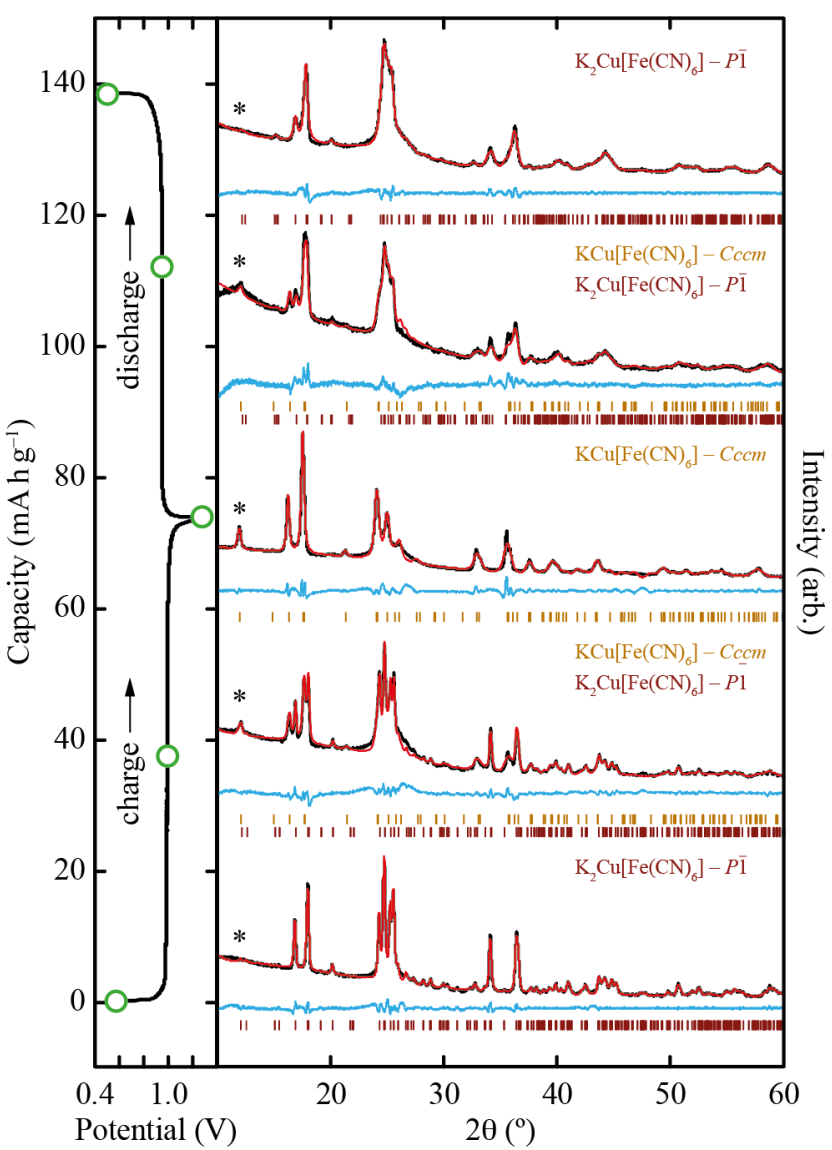

Figure 6: Ex situ X-ray powder diffraction measurements $(\lambda=1.541 \AA)$ for $\mathrm{K}_{2-x} \mathrm{Cu}\left[\mathrm{Fe}(\mathrm{CN})_{6}\right]$ samples taken from different key points in the first charge/discharge cycle. Data are shown as black points; fits as red lines; and the difference (data - fit) as blue lines. Tick marks show the allowed reflection positions for both $P \overline{1}$ (dark red) and $\mathrm{Cccm}$ (sand) phases. The reflections marked with an asterisk are sensitive to $\mathrm{X}_{5}^{+}$cation order.

A peculiarity of both $P \overline{1}$ and $C c c m$ structures to which we have already alluded is that they contain two crystallographically-distinct K-ion sites. This reflects the $\mathrm{X}_{4}^{+}$cation order we know to be present. In the case of the $C c c m \mathrm{KCu}\left[\mathrm{Fe}(\mathrm{CN})_{6}\right]$ (fully charged) phase, there is clear evidence for $\mathrm{K}^{+} /$vacancy order: the emergence of diffraction intensity near $12^{\circ}$ in $2 \theta$ is characteristic. $^{1}$ A structural model with equal K-ion occupancies on the two crystallographically-distinct sites gives no appreciable intensity at this position-after all, this is why there is no intensity here for the fullypotassiated phase. Hence there is selective extraction of $\mathrm{K}^{+}$ions from just one subset of the K-ion channels in $\mathrm{K}_{2} \mathrm{Cu}\left[\mathrm{Fe}(\mathrm{CN})_{6}\right]$. Unfortunately, our data are not of

\footnotetext{
${ }^{1}$ This $12^{\circ}$ peak corresponds to the 110 reflection of the $F m \overline{3} m$ aristotype; note also the different X-ray wavelength used for these ex situ measurements when comparing to the data shown in Figs. 2,4.
} 
sufficiently high quality to allow robust Rietveld refinement of the corresponding occupancies.

DFT calculations also reflect this preference for cooperative K-ion extraction. Starting with the relaxed $P \overline{1}$ structure described above, we removed in turn all possible combinations of two of the four potassium ions in its unit cell and then re-relaxed the corresponding structures. The two configurations with rod-like $\left(\mathrm{X}_{4}^{+}\right) \mathrm{K}$-ion/vacancy order relaxed to lower energies ( $\sim 6 \mathrm{meV} /$ atom) than other combinations. Interestingly, in the resulting $\mathrm{KCu}\left[\mathrm{Fe}(\mathrm{CN})_{6}\right]$ structures there persisted some off-centering of the $\mathrm{K}^{+}$ions which reduced the symmetry from $C c c m$ to $P \overline{1}$. This suggests that the $C c c m$ structure type we observe may be unstable with respect to a slide distortion at $0 \mathrm{~K}$; presumably it is simply that the critical temperature at which the distortion occurs is below room temperature. This is the same instability that we have observed (in reverse) when heating the fully-potassiated phase, for which the critical temperature is understandably much higher.

As a final point, we note that the increased peak broadening observed on discharge is probably due to a combination of particle size reduction and also domain formation during symmetry lowering. We comment also that it is not our intention here to investigate fully the cycling capacity of $\mathrm{K}_{2} \mathrm{Cu}\left[\mathrm{Fe}(\mathrm{CN})_{6}\right]$, nor the effect of different electrolytes, nor the potential differences between in situ and ex situ observations; ${ }^{50}$ we expect to follow up on these aspects in a future study. We note simply that the initial capacity observed (73.8 $\mathrm{mA} \mathrm{h} \mathrm{g}^{-1}$ ) certainly compares favourably against that of the better-known $\mathrm{K}_{0.71} \mathrm{Cu}\left[\mathrm{Fe}(\mathrm{CN})_{6}\right]_{0.72}$ phase $\left(59.1 \mathrm{~mA} \mathrm{~h}^{-1}\right) .{ }^{18}$

\section{Concluding Remarks}

In summary, we have prepared and characterised the new PBA material $\mathrm{K}_{2} \mathrm{Cu}\left[\mathrm{Fe}(\mathrm{CN})_{6}\right]$. Its complex triclinic structure arises from the interplay of K-ion slides, octahedral tilts, cooperative Jahn-Teller order, and rodlike K-ion occupational order. Of these various distortions, the $\mathrm{K}$-ion slides are what dominate the structural response of the material. We see this both in terms of the behaviour at high temperatures and also the structural changes that take place during electrochemical cycling. As esoteric as the various symmetry considerations associated with combining distortions might seem, one very physical consequence is that $\mathrm{K}$-ion extraction proceeds via a two-phase mechanism to give a charged phase with rod-like K-ion order. This implies a specific migration pathway. A schematic representation

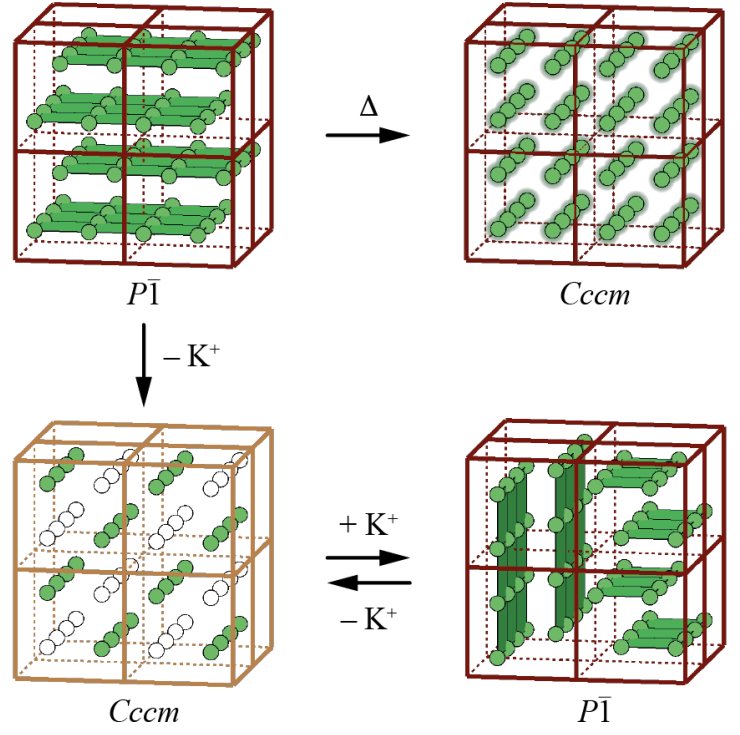

Figure 7: Schematic representation of the structural transformations in $\mathrm{K}_{2} \mathrm{Cu}\left[\mathrm{Fe}(\mathrm{CN})_{6}\right]$ that take place as a function of temperature and electrochemical cycling. On heating, increased K-ion displacements (shown here as blurred green spheres) result in 'melting' of the K-ion slide distortion and the ascent in symmetry from $P \overline{1}$ to $C \mathrm{ccm}$. Likewise, electrochemical extraction of $\mathrm{K}^{+}$from the ambient $P \overline{1}$ phase gives $\mathrm{KCu}\left[\mathrm{Fe}(\mathrm{CN})_{6}\right]$ with rod-like A-site vacancy order that again disrupts the slide distortion. Subsequent reinsertion of $\mathrm{K}^{+}$reactivates the $\mathrm{K}$-ion slides, albeit in domains of smaller coherence length than in the pristine sample. Dark-red and sand-coloured frames denote the $2+/ 3+$ charge state of Fe.

of these various transformations is given in Fig. 7.

At face value, the structural transformations taking place during $\mathrm{K}$-ion (de)insertion in $\mathrm{K}_{2} \mathrm{Cu}\left[\mathrm{Fe}(\mathrm{CN})_{6}\right]$ perhaps seem very much more complicated than the solid-solution cubic-phase behaviour of other PBAs. But of course it is only because the various distortions are ordered in our new material that we can see what is actually going on. There can be no doubt that disordered phases such as $\mathrm{K}_{0.71} \mathrm{Cu}\left[\mathrm{Fe}(\mathrm{CN})_{6}\right]_{0.72}$ exhibit the very same types of distortions we discuss hereit is simply that these distortions are correlated only over relatively small distances. Nevertheless the symmetry arguments we apply to our ordered phase will still affect the local behaviour of these disordered materials. So we now know there must be strong coupling between e.g. local Jahn-Teller order and the orientation of vacant A-site channels in $\mathrm{K}_{0.71} \mathrm{Cu}\left[\mathrm{Fe}(\mathrm{CN})_{6}\right]_{0.72}$, even if there is no obvious signature of this in the average crystal structure. Our identification of the key symmetry-lowering mechanisms at play also simplifies the use of pair distribution function measurements to characterise the local structure and its evolution in these important and useful cathode materials. ${ }^{51,52}$ 
Acknowledgement The authors thank the E.R.C. (Advanced Grant 788144), the ISCF Faraday Challenge project SOLBAT (grant number FIRG026) and the Henry Royce Institute (through UK Engineering and Physical Science Research Council grant EP/R010145/1) for funding and capital equipment. The authors acknowledge the provision of a BAG allocation (CY25166) on the I11 beamline at the Diamond Light Source, U.K. Assistance from M. Schart (Oxford) with SEM measurements and P. Bergstrom Mann (Oxford) with ICP measurements is greatly appreciated.

\section{Supporting Information Avail- able}

The following files are available free of charge.

- Supplementary information file (.pdf).

\section{References}

(1) Goodenough, J. B. Jahn-Teller Phenomena in Solids. Annu. Rev. Mater. Sci. 1998, 28, 1-27.

(2) Hill, N. A. Why are there so few magnetic ferroelectrics? J. Phys. Chem B. 2000, 104, 6694 6709.

(3) Tokura, Y.; Nagaosa, N. Orbital physics in transition-metal oxides. Science 2000, 288, 462 468.

(4) Van Aken, B. B.; Palstra, T. T. M.; Filippetti, A.; Spaldin, N. A. The origin of ferroelectricity in magnetoelectric $\mathrm{YMnO}_{3}$. Nat. Mater. 2004, 3, 164-170.

(5) Pitcher, M.; Mandal, P.; Dyer, M.; Alaria, J.; Borisov, P.; Niu, H.; Claridge, J. B.; Rosseinsky, M. J. Tilt engineering of spontaneous polarization and magnetization above $300 \mathrm{~K}$ in a bulk layered perovskite. Science 2015, 347, 420-424.

(6) Goodenough, J. B. Theory of the Role of Covalence in the Perovskite-Type Manganites [La, $M(\mathrm{II}) \mathrm{MnO}_{3}$. Phys. Rev. 1955, 100, 564-573.

(7) Rao, C. N. R.; Cheetham, A. K. Giant Magnetoresistance in Transition Metal Oxides. Science 1996, 272, 369-370.
(8) Dagotto, E.; Hotta, T.; Moreo, A. Colossal Magnetoresistant Materials: The Key Role of Phase Separation. Phys. Rep. 2001, 344, 1-153.

(9) Benedek, N. A.; Fennie, C. J. Hybrid improper ferroelectricity: A mechanism for controllable polarization-magnetization coupling. Phys. Rev. Lett. 2011, 106, 107204.

(10) Boström, H. L. B.; Senn, M. S.; Goodwin, A. L. Recipes for improper ferroelectricity in molecular perovskites. Nat. Commun. 2018, 9, 2380.

(11) Stroppa, A.; Jain, P.; Barone, P.; Marsman, M.; Perez-Mato, J. M.; Cheetham, A. K.; Kroto, H. W.; Picozzi, S. Electric control of magnetization and interplay between orbital ordering and ferroelectricity in a multiferroic metalorganic framework. Angew. Chem. 2011, 50, $5847-5850$.

(12) Li, W.; Wang, Z.; Deschler, F.; Gao, S.; Friend, R. H.; Cheetham, A. K. Chemically diverse and multifunctional hybrid organicinorganic perovskites. Nat. Rev. Mater. 2017, 2, 16099.

(13) Boström, H. L. B.; Goodwin, A. L. Hybrid Perovskites, Metal-Organic Frameworks, and Beyond: Unconventional Degrees of Freedom in Molecular Frameworks. Acc. Chem. Res. 2021, 54, 1288-1297.

(14) Keggin, J. F.; Miles, F. Structures and Formulæ of the Prussian Blues and Related Compounds. $\mathrm{Na}$ ture 1936, 137, 577-578.

(15) Wilde, R. E.; Ghosh, S. N.; Marshall, B. J. The Prussian Blues. Inorg. Chem. 1970, 9, 25122516.

(16) Dunbar, K. R.; Heintz, R. A. Chemistry of Transition Metal Cyanide Compounds: Modern Perspectives. Prog. Inorg. Chem. 1997, 45, 283-391.

(17) Verdaguer, M.; Girolami, G. In Molecules to Materials V; Miller, J. S., Drillon, M., Eds.; WILEYVCH Verlag GmbH \& Co. KGaA: Weinheim, 2004; pp 283-346.

(18) Wessells, C. D.; Huggins, R. A.; Cui, Y. Copper hexacyanoferrate battery electrodes with long cycle life and high power. Nat. Commun. 2011, 2, 550 . 
(19) Hurlbutt, K.; Wheeler, S.; Capone, I.; Pasta, M. Prussian Blue Analogs as Battery Materials. Joule 2018, 2, 1950-1960.

(20) Dhir, S.; Wheeler, S.; Capone, I.; Pasta, M. Outlook on K-Ion Batteries. Chem 2020, 6, 24422460 .

(21) Riemers, J. N.; Dahn, J. Electrochemical and in situ X-ray diffraction studies of lithium intercalation in $\mathrm{Li}_{x} \mathrm{CoO}_{2}$. J. Electrochem. Soc. 1992, 139, 2091-2097.

(22) Cattermull, J.; Pasta, M.; Goodwin, A. L. Structural complexity in Prussian blue analogues. Mater. Horiz. 2021, 8, 3178-3186.

(23) Boström, H. L. B.; Brant, W. R. Octahedral tilting in Prussian blue analogues. arXiv: 2022, 2201.02467.

(24) Allen, D. J. W.; Bristowe, N. C.; Goodwin, A. L.; Yeung, H. H.-M. Mechanisms for collective inversion-symmetry breaking in dabconium perovskite ferroelectrics. J. Mater. Chem. C 2021, 9 , 2706-2711.

(25) Fiore, M.; Wheeler, S.; Hurlbutt, K.; Capone, I.; Fawdon, J.; Ruffo, R.; Pasta, M. Paving the Way toward Highly Efficient, High-Energy PotassiumIon Batteries with Ionic Liquid Electrolytes. Chem. Mater. 2020, 32, 7653-7661.

(26) Bie, X.; Kubota, K.; Hosaka, T.; Chihara, K.; Komaba, S. A novel K-ion battery: hexacyanoferrate(II)/graphite cell. J. Mater. Chem. A 2017, $5,4325-4330$.

(27) Buser, H.-J.; Ron, G.; Ludi, A.; Engel, P. Crystal Structure of Cadmium Hexacyanopalladate(IV). J. Chem. Soc., Dalton Trans. 1974, 2473-2474.

(28) Chapman, K. W.; Chupas, P. J.; Kepert, C. J. Compositional dependence of negative thermal expansion in the Prussian Blue analogues $\mathrm{M}(\mathrm{II}) \operatorname{Pt}(\mathrm{IV})(\mathrm{CN})_{6}(\mathrm{M}=\mathrm{Mn}, \mathrm{Fe}, \mathrm{Co}, \mathrm{Ni}, \mathrm{Cu}, \mathrm{Zn}$, Cd). J. Am. Chem. Soc. 2006, 128, 7009-7014.

(29) Coelho, A. A. TOPAS-Academic, version 6. 2016, Coelho Software: Brisbane.

(30) Kresse, G.; Furthmüller, J.; Hafner, J. Theory of the crystal structures of selenium and tellurium: The effect of generalized-gradient corrections to the local-density approximation. Phys. Rev. B 1994, 50, 13181-13185.
(31) Kresse, G.; Furthmüller, J. Efficiency of ab-initio total energy calculations for metals and semiconductors using a plane-wave basis set. Comp. Mater. Sci. 1996, 6, 15-50.

(32) Heyd, J.; Scuseria, G. E.; Ernzerhof, M. Hybrid functionals based on a screened Coulomb potential. J. Chem. Phys. 2003, 118, 8207-8215.

(33) Krukau, A. V.; Vydrov, O. A.; Izmaylov, A. F.; Scuseria, G. E. Influence of the exchange screening parameter on the performance of screened hybrid functionals. J. Chem. Phys. 2006, 125, 224106.

(34) Wang, K.; Jacobsen, S. B. An estimate of the Bulk Silicate Earth potassium isotopic composition based on MC-ICPMS measurements of basalts. Geochim. Cosmochim. Acta 2016, 178, 223-232.

(35) Glazer, A. M. The Classification of Tilted Octahedra in Perovskites. Acta Cryst. B 1972, 28, 33843392.

(36) Howard, C. J.; Kennedy, B. J.; Woodward, P. M. Ordered double perovskites - a group-theoretical analysis. Acta Cryst. B 2003, 59, 463-471.

(37) Stokes, H. T.; Hatch, D. M.; Campbell, B. J. ISODISTORT, ISOTROPY Software Suite. iso.byu.edu.

(38) Campbell, B. J.; Stokes, H. T.; Tanner, D. E.; Hatch, D. M. ISODISPLACE: A web-based tool for exploring structural distortions. J. Appl. Cryst. 2006, 39, 607-614.

(39) Boström, H. L. B.; Smith, R. I. Structure and thermal expansion of the distorted Prussian blue analogue $\mathrm{RbCuCo}(\mathrm{CN})_{6}$. Chem. Commun. 2019, 55, 10230-10233.

(40) Howard, C. J.; Stokes, H. T. Group-Theoretical Analysis of Octahedral Tilting in Perovskites. Acta Cryst. B 1998, 54, 782-789.

(41) Howard, C. J.; Carpenter, M. A. Octahedral tilting in cation-ordered Jahn-Teller distorted perovskites - a group-theoretical analysis. Acta Cryst. B 2010, 66, 40-50.

(42) Matsuda, T.; Kim, J.; Moritomo, Y. Control of the alkali cation alignment in Prussian blue framework. Dalton Trans. 2012, 41, 7620-7623. 
(43) Hurlbutt, K.; Giustino, F.; Pasta, M.; Volonakis, G. Electronic structure and electrontransport properties of three metal hexacyanoferrates. Chem. Mater. 2021, 33, 7067-7074.

(44) Goodwin, A. L.; Calleja, M.; Conterio, M. J.; Dove, M. T.; Evans, J. S. O.; Keen, D. A.; Peters, L.; Tucker, M. G. Colossal positive and negative thermal expansion in the framework material $\mathrm{Ag}_{3}\left[\mathrm{Co}(\mathrm{CN})_{6}\right]$. Science 2008, 319, 794-797.

(45) Åkerblom, I. E.; Ojwang, D. O.; Grins, J.; Svensson, G. A thermogravimetric study of thermal dehydration of copper hexacyanoferrate by means of model-free kinetic analysis. J. Therm. Anal. Calorim. 2017, 129, 721-731.

(46) Cromer, D. T. The crystal structure of $\mathrm{KCu}(\mathrm{CN})_{2}$. J. Phys. Chem. 1957, 61, 1388-1392.

(47) Barber, H. J. Cuprous cyanide: A note on its preparation and use. J. Chem. Soc. 1943, 79-80.

(48) Sharpe, A. G. The Chemistry of Cyano Complexes of the Transition Metals; Academic Press: London, 1976.

(49) Simonov, A.; De Baerdemaeker, T.; Boström, H. L. B.; Ríos Gómez, M. L.; Gray, H. J.; Chernyshov, D.; Bosak, A.; Bürgi, H.-B.; Goodwin, A. L. Hidden diversity of vacancy networks in Prussian blue analogues. Nature 2020, 578, 256-260.

(50) Liu, H.; Strobridge, F. C.; Borkiewicz, O. J.; Wiaderek, K. M.; Chapman, K. W.; Chupas, P. J.; Grey, C. P. Capturing metastable structures during high-rate cycling of $\mathrm{LiFePO}_{4}$ nanparticle electrodes. Science 2014, 344, 1252817.

(51) Chapman, K. W.; Chupas, P. J.; Kepert, C. J. Selective Recovery of Dynamic Guest Structure in a Nanoporous Prussian Blue through in Situ Xray Diffraction: A Differential Pair Distribution Function Analysis. J. Am. Chem. Soc. 2005, 127, 11232-11233.

(52) Chapman, K. W.; Beyer, K. A.; Zhao, H.; Chupas, P. J. Correlating structure and chemistry through simultaneous in situ pair distribution function and infrared spectroscopy measurements. CrystEngComm 2013, 15, 9377-9381. 